\title{
PROCESSOS EROSIVOS EM ÁREA URBANA E AS IMPLICAÇÕES NA QUALIDADE DE VIDA
}

\author{
EROSIONAL PROCESSES IN URBAN AREA AND \\ IMPLICATIONS ON QUALITY OF LIFE
}

\author{
PROCESOS EROSIVOS EN ÁREA URBANA Y SUS \\ IMPACTOSEN LA CALIDAD DE VIDA
}
Andrelisa Santos de Jesus - Universidade Federal de Goiás - Goiânia - Goiás - Brasil
andrelisa.jesus@gmail.com

\author{
José Camapum de Carvalho - Universidade de Brasília - Brasília - Distrito Federal - Brasil \\ camapumdecarvalho@gmail.com
}

\begin{abstract}
Resumo
Países com solos tropicais tendem, quando não adotam práticas adequadas de uso do solo, a sofrer com fenômenos de erosão linear. Esta pesquisa investigou de forma qualitativa, usando parâmetros da Organização Mundial da Saúde (OMS), a população que habita o entorno de voçorocas na cidade de Anápolis - G0. 0 principal objetivo da pesquisa foi discutir novas possibilidades de abordagem do fenômeno erosivo, evidenciando em suas causas e consequências a influência de fatores socioeconômicos e de educação. Em 2012 foram abordadas 72 residências no entorno de erosões, onde um representante conversava com 0 entrevistador fornecendo dados de todos os moradores da casa. Esse procedimento permitiu a aquisição de informações de um total de 264 pessoas. A análise dos dados revelou um perfil socioeconômico de baixa escolaridade, subempregos e baixos salários, bem como deficiência de infraestrutura urbana e de acesso a serviços urbanos e de lazer. Além disso, constatou-se uma dificuldade por parte da população em perceber o meio físico dos locais habitados, bem como os riscos inerentes aos impactos neles existentes, tais como as voçorocas. Tal situação demonstra uma necessidade eminente de ações governamentais de ordenamento do uso do solo e de educação ambiental formal e informal que permitam a efetivação de atitudes preventivas à instalação de processos erosivos lineares.
\end{abstract}

Palavras-chave: Voçoroca, solo, meio ambiente.

\section{Abstract}

Countries with tropical soils tend to struggle with linear erosion phenomena by not adopting appropriate land use practices. Based on WHO standards, this qualitative research study examined the population living close to gullies in the city of Anápolis, Goiás state, Brazil. The study's main objective was to discuss new possibilities of addressing erosion, highlighting the influence of socio-economic and educational factors on its causes and outcomes. Seventy-two houses located around eroding areas were investigated in 2012, and in each of them an individual provided the interviewer with information regarding all its residents; this procedure resulted in a data set with information about 264 people. Data analysis produced a socio-economic profile of low educational level, underemployment, and low salaries, as well as deficiency in urban infrastructure and in access to urban and leisure services. Moreover, the analysis revealed that the population has difficulties in perceiving the physical environment of the places they live in as well as the inherent risks posed by existing impacts, e.g. gullies. This scenario exposes the imminent need for governmental actions concerning land use planning and environmental education (both formal and informal) which establish preventive measures against the emergence of linear erosion processes.

Keywords: Gully, soil, environment. 


\section{Resumen}

Países con suelos tropicales, cuando no adoptan prácticas adecuadas de uso del suelo, tienden a sufrir fenómenos de erosión linear. Esta investigación estudió, de forma cualitativa, usando parámetros de la OMS, la población que habita los alrededores de las cárcavas en la ciudad de Anápolis - GO. El principal objetivo de esta investigación fue discutir nuevas posibilidades para enfocar el fenómeno erosivo, evidenciando en sus causas y consecuencias la influencia de factores socioeconómicos y de educación. En 2012 fueron estudiadas72 residencias situadas alrededor de las erosiones, donde un representante conversaba con el entrevistador forneciendo los datos de todos los habitantes de la casa. Ese procedimiento permitió la adquisición de informaciones de un total de 264 personas. El análisis de los datos mostró un perfil socioeconómico de baja escolaridad, subempleos y salarios bajos, así como la deficiencia de infraestructura urbana y acceso a servicios urbanos y de entretenimiento. Además, se constató la dificultad de percibir el medio físico de los locales habitados, así como los riesgos inherentes a los impactos que existen en los mismos, como por ejemplo las cárcavas. Eso demuestra la necesidad inminente de ordenamiento gubernamental sobre el uso del suelo y sobre la educación ambiental formal e informal que permitan la efectivización de acciones preventivas de procesos erosivos lineares.

Palabras clave: Cárcava, suelo, medio ambiente.

\section{Introdução}

Ao falar de erosão de solos com profissionais de áreas diversas, as percepções serão igualmente distintas, pois cada um deles privilegiará as diretrizes conceituais e pragmáticas de sua formação teórica. O que une esses profissionais é o estudo das causas do processo erosivo, mesmo que, por vezes, muitos deles procurem as causas de forma isolada no contexto ambiental. Além disso, entre os que procuram por soluções, nem sempre estas estão vinculadas às causas ambientalmente contextualizadas. Dentre outros, alguns profissionais merecem destaque, no que tange aos estudos sobre erosão: agrônomos, engenheiros geotécnicos, geógrafos, geólogos, gestores públicos (prefeitos, governadores).

E o morador do entorno da erosão? Em que circunstâncias ele é pensado quando se estudam as causas do processo? Onde ele se encaixa em estudos das consequências do processo? Principalmente, quando ele é pensado no ato das escolhas das soluções mais acertadas para o local? Como sua qualidade de vida pode ser afetada pela dinâmica do processo erosivo?

Ousa-se dizer que poucos profissionais técnicos têm se indagado sobre o que diria da erosão uma pessoa que habita o seu entorno ou que habitou um local por ela arrasado. Assim, com foco na população que habita o entorno das erosões lineares do tipo voçoroca, procurou-se, dentro deste trabalho, investigar quem são essas pessoas, como se relacionam com as erosões e como essas erosões interferem na sua qualidade de vida. Afinal, como apontam Bertoni e Lombardi Neto (1999), a erosão não é só um problema técnico, mas também um problema socioeconômico, visto 
que o êxito em ações de conservação do solo depende do conjunto de implicações sociais e econômicas.

Não foi pretensão desta pesquisa produzir índices de qualidade de vida, mas sim discutir os vários indicadores associados a esse conceito. Desse modo, apresenta-se uma nova possibilidade de abordagem dos processos erosivos acelerados cujas causas e consequências sociais são, em geral, superficializadas e encobertas por preocupações puramente vinculadas ao fenômeno físico por parte de geólogos, engenheiros e geógrafos ou por preocupações meramente imediatistas da gestão pública. As pessoas que habitam o entorno de erosões não são apenas um número na estatística populacional, elas têm uma história, sentimentos e necessidades que as fazem se sujeitarem ao ambiente de risco do entorno das erosões, colocando-as à sorte de vários tipos de problemas que vão além de acidentes envolvendo danos às edificações, conforme será apresentado neste artigo (Figura 1).

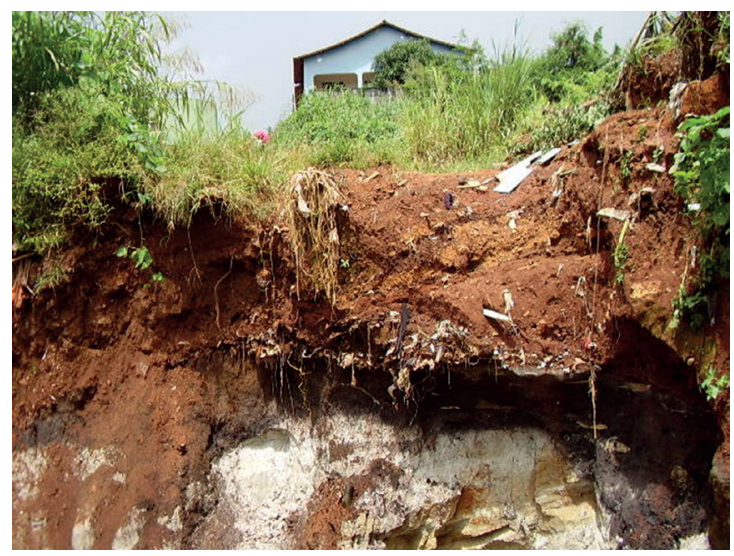

Figura 1 - Em primeiro plano talude da voçoroca denominada Cidade Jardim e em segundo plano uma das várias casas que estão localizadas próximas a essa voçoroca.

Fonte: Jesus (2013)

\section{Metodologia}

Foram selecionadas, na área urbana da cidade de Anápolis GO, sete incisões erosivas do tipo voçoroca para serem estudadas mais detalhadamente (Figura 2). Essas voçorocas são representativas 
dos compartimentos geomorfológicos onde estão inseridas, sendo que quatro destas estão na porção leste da área de estudo, onde a dissecação e as declividades são menos acentuadas, e outras três estão na porção oeste, muito dissecada e com declividades muito elevadas. A seleção das voçorocas também levou em conta a própria tipologia das incisões erosivas, tendo sido selecionadas duas voçorocas de vertente, uma de drenagem e quatro de cabeceiras de drenagem. As referidas voçorocas foram denominadas nesse trabalho da seguinte forma: Voçoroca Túnel (VT), Voçoroca Contorno (VC), Voçoroca Geovane Braga (VGB), Voçoroca Cidade Jardim (VCJ), Voçoroca Colégio Estadual (VCE), Voçoroca Leopoldo de Bulhões (VLB) e Voçoroca Frei Eustáquio (VFE).

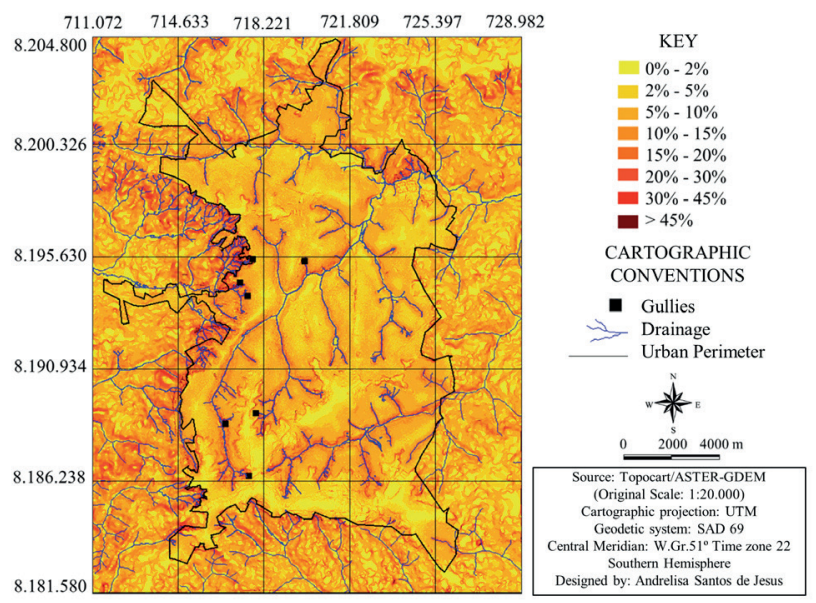

Figura 2 - Mapa de declividade da área urbana e periurbana de Anápolis, G0, destacando as voçorocas estudadas nesta pesquisa.

No ano de 2012, foram realizadas entrevistas com os moradores do entorno dessas erosões. A metodologia de elaboração do guia de entrevistas baseou-se na proposta de Jesus (2007), que conversou com moradores da alta bacia do rio das Antas em Anápolis - GO, com o mesmo propósito apresentado por esta pesquisa. Além disso, as questões que compunham o guia de entrevistas também seguiram as proposições de Coelho (2001), contemplando campos que revelam as condições socioeconômicas da população. É importante salientar que o guia de entrevistas utilizadas nesta pesquisa atenta para os itens abordados pelo domínio de meio ambiente proposto pela Organização Mundial da Saúde (OMS). 
Foram abordados indicadores vinculados à escolaridade, situação profissional, rentabilidade, origem do morador, condições de moradia, infraestrutura urbana, serviços disponíveis, acesso a lazer e informação, percepção do local onde mora e articulação sociopolítica. Foram realizadas entrevistas em 72 residências, onde um representante maior de idade conversava com o entrevistador fornecendo dados de todos os moradores da casa. Dessa maneira foi possível adquirir informações de um total de 264 pessoas. A quantidade de residências entrevistadas não foi igual em todas as incisões erosivas (Gráfico 1). $\mathrm{O}$ acesso às residências dependeu de vários fatores, dentre eles: presença de morador, disponibilidade e permissão do morador em participar da pesquisa, tamanho da erosão e quantidade de casas próximas à erosão. Não foram realizadas entrevistas no entorno da voçoroca Túnel, pois ela está numa área periférica à ocupação urbana, sem residências em suas proximidades.

Enfatiza-se, portanto, o caráter qualitativo da pesquisa, em que se tentou transcender a frieza estática dos números, percentuais e questionários a que está vinculada boa parte dos dados, revelando os anseios dos moradores. Afinal, esses moradores muitas vezes são lembrados apenas de maneira pontual em manchetes de tragédias que marcam de modo profundo e irreversível suas vidas. Esse caráter qualitativo segue os princípios do trabalho de Jesus (2007) e de Jesus, Lopes e Carvalho (2009), em estudo semelhante, mas limitado à alta bacia do rio das Antas em Anápolis - GO, onde o elemento mais importante e valoroso apreendido pelos autores foram os sentimentos dos moradores.

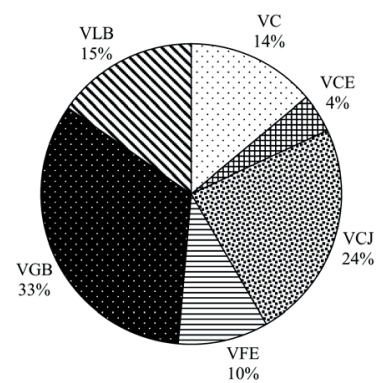

(a)

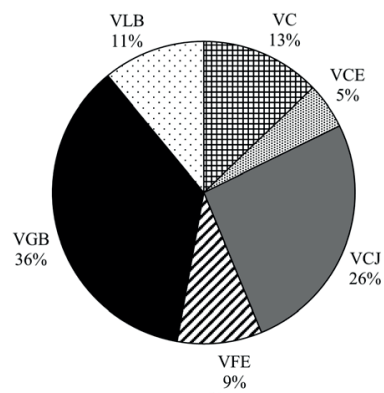

(b)

Gráfico 1 - Amostragem das entrevistas: (a) distribuição de residências entrevistadas por voçoroca; (b) distribuição de pessoas entrevistadas por voçoroca. 


\section{Resultados e discussões}

Entre os moradores entrevistados, verificou-se que 24\% das pessoas estavam cursando o ensino básico e que 37\% das pessoas possuem educação básica inconclusa. Verificou-se ainda que 17\% dos entrevistados concluíram a educação básica, mas não tiveram acesso ao ensino superior. Apenas $14 \%$ das pessoas abordadas na pesquisa alcançaram o ensino superior (Gráfico 2).

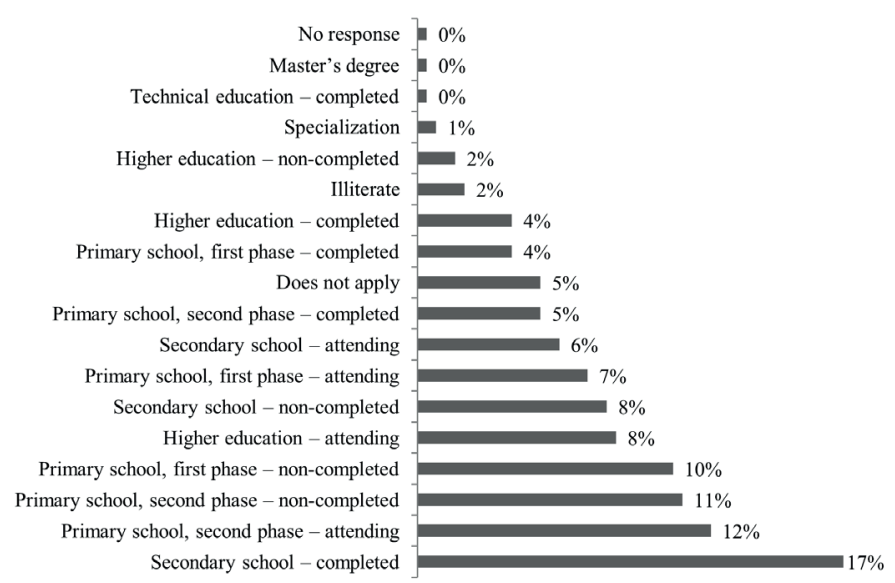

Gráfico 2 - Grau de escolaridade dos moradores que habitam o entorno das erosões.

Fonte: Jesus (2013).

No que tange à situação profissional dos moradores abordados na pesquisa, levou-se em consideração a idade laboral de início das atividades profissionais conforme regulamentado na Emenda $\mathrm{n}^{\circ} 20$, de 16 de dezembro de 1998, que determina 16 anos como o marco inicial da vida laboral. Desse modo, verificou-se que $37 \%$ dos moradores abordados na pesquisa foram agrupados na classe "não se aplica" (Figura 5a). Mas esse percentual esconde 5\% que não informaram sua condição laboral, $1 \%$ que declarou nunca ter trabalhado, 13\% de menores de 16 anos, 20\% de donas de casa e 60\% correspondentes a estudantes (Gráfico 3b).

Para o universo estatístico em condição laboral, foi possível verificar que $41 \%$ dos trabalhadores estavam empregados em empregos formais. Mas um percentual relevante de $35 \%$ da amostra encontrava-se vinculado 
a trabalhos informais. Além disso, $8 \%$ dos trabalhadores estavam desempregados, sendo que dentre esses, a grande maioria, ou seja, $47 \%$ desse percentual, se encontrava, na data da pesquisa, desempregada há menos de seis meses e, um percentual considerável de 27\%, desempregado há dois anos (Gráfico 3c).

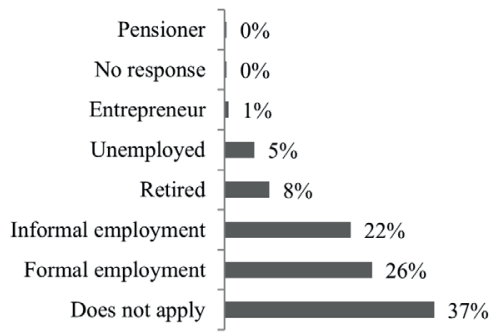

(a)

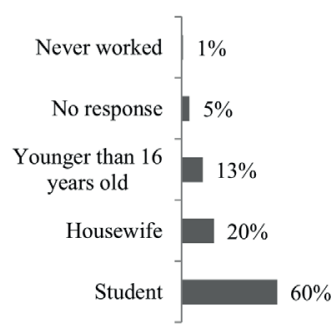

(b)

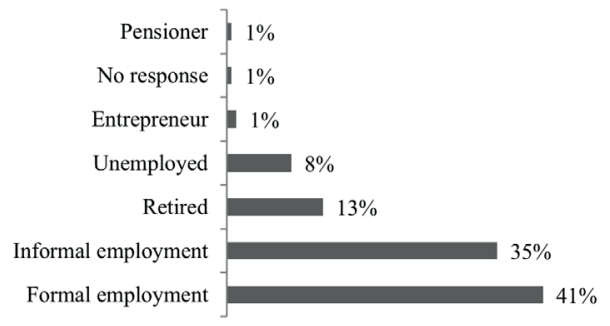

(c)

Gráfico 3 - Dados laborais dos moradores: (a) condição laboral no período da pesquisa; (b) especificação da classe onde não se aplica condição laboral; (c) universo estatístico em condição laboral.

Fonte: Jesus (2013).

O alto percentual de empregos informais pode ter uma relação direta com a escolaridade dos moradores, que majoritariamente possuem o ensino básico incompleto. Tal situação suscita a existência de uma mão de obra desqualificada, que em geral é um fator importante no que se refere à inserção no mercado formal de empregos e consequentemente de acesso a boa remuneração. Situação semelhante foi verificada por Jesus (2007) e Jesus, Lopes e Carvalho (2009) na alta bacia do rio das Antas, onde a combinação baixa escolaridade e informalidade profissional resultou em renda muito pequena. 
A abordagem da renda entre os moradores que fazem parte desta pesquisa foi realizada considerando o salário mínimo de R \$ 622,00 (seiscentos e vinte e dois reais), que passou a vigorar no Brasil a partir de primeiro de janeiro de 2012, conforme o Decreto $n^{\circ} 7.655$ (Brasil, 2011). Entre os moradores entrevistados que realizavam atividades com remuneração verificou-se que a grande maioria de $64 \%$ possuía rendimentos entre um e dois salários mínimos. Ao considerar a renda familiar, somando os rendimentos de todos os membros da residência, constata-se que a maioria, $52 \%$ das famílias, vive com renda entre um e dois salários mínimos.

A baixa renda verificada nesta pesquisa, entre os moradores, confirma uma realidade já demonstrada pelo IBGE (2010), que aponta para o fato de 39\% dos domicílios em Anápolis possuírem uma renda familiar de até dois salários mínimos. Se for levada em consideração uma renda de até cinco salários mínimos, esse percentual se eleva para 78\%. Essa baixa renda familiar é reconhecida pela Prefeitura Municipal de Anápolis no relatório do Plano Diretor (Anápolis, 2006).

A tríade baixa escolaridade, emprego informal e renda baixa pode induzir e sustentar um indicativo de marginalização social, especialmente no que se refere à moradia. De acordo com Santos (2008, p. 144),

[...] uma família com renda de até 3 ou 4 salários mínimos somente consegue constituir moradia, própria ou alugada, com alguma combinação entre as seguintes variáveis: distância, periculosidade, insalubridade, desconforto ambiental, precariedade construtiva e irregularidade fundiária.

Quando se trata dos ensejos da escolha do atual bairro para morar, $36 \%$ dos entrevistados apontam que o principal motivo da mudança foi acesso à moradia, sendo $29 \%$ e $7 \%$, respectivamente, referentes à casa própria e valor acessível do aluguel. Embora próximo às erosões, a localização do loteamento também aparece com um percentual relevante (21\%) entre os motivos de escolha do bairro.

A razão de a localização estar entre um dos principais motivos para morar no bairro se deve ao fato de a maioria dos bairros abordados ficar próxima ao centro, que, em Anápolis - GO, ainda centraliza boa parte dos serviços e comércio. No caso dos bairros mais distantes, a localização ainda aparece como fator relevante, pois muitas vezes aproxima o morador do seu local de trabalho, como é o caso dos bairros Geovane Braga e 
Polocentro, vizinhos ao Distrito Agroindustrial de Anápolis - DAIA. Essas peculiaridades demonstram a importância das características de qualidade que deve ter o Plano Diretor, fundamentando-se em estudos preliminares quanto aos limites de uso e ocupação do solo visando priorizar as questões socioambientais.

A grande maioria, 61\% dos moradores, residia em casas próprias, e os demais 39\% em residências alugadas. Dos que moravam de aluguel, $53 \%$ pagavam de $\mathrm{R} \$ 250,00$ (duzentos e cinquenta reais) a $\mathrm{R} \$ 622,00$ (seiscentos e vinte e dois reais) e 36\% pagavam até $\mathrm{R} \$ 250,00$ (duzentos e cinquenta reais). Ao associar o indicador de rentabilidade com o valor do aluguel, é possível inferir que as despesas com a moradia devem pesar muito sobre o orçamento dessas famílias, uma vez que a renda da maioria não ultrapassa dois salários mínimos. Em alguns casos, o valor do aluguel pode comprometer a metade do orçamento familiar. Logo, como afirma Carlos (2001, p. 79), o "homem vive onde ele pode morar e isso será determinado por sua renda e pelos sacrifícios que pode fazer". E no caso dos moradores abordados nesta pesquisa, eles podem viver e pagar para morar próximos a incisões erosivas.

No que diz respeito à infraestrutura da área estudada, a maioria das residências conta com iluminação pública, abastecimento de água por meio de rede canalizada, galeria de águas pluviais e pavimentação asfáltica. Todavia, no que se refere à rede coletora de esgoto, apenas $24 \%$ das residências são atendidas, sendo que a grande maioria de $75 \%$ utiliza a fossa séptica para eliminação de esgotos.

Destaca-se que, quanto à drenagem de águas pluviais, por vezes a evacuação é inapropriada, seja no que diz respeito às condições de lançamento, gerando erosões, seja quanto ao volume captado e lançado nos talvegues e cursos d'água, provocando inundações a jusante.

Embora a maioria significativa de 96\% dos moradores entrevistados contasse com o serviço de coleta de lixo, aproximadamente $6 \%$ desses moradores lançam lixo na erosão ou descartam o lixo a ser coletado de maneira imprópria, colocando as sacolas diretamente sobre a calçada. Entre os que não contam com a coleta de lixo, o descarte é feito por lançamento na erosão ou em lotes baldios.

No que se refere à segurança, 58\% dos moradores não consideravam o local violento, mas entre esses moradores a grande maioria não justificou sua opinião. Já entre os $42 \%$ dos entrevistados que consideraram o local 
onde vivem violento, estes justificaram sua afirmativa por ocorrências de roubos e furtos, drogas e assassinatos (respectivamente, 37\%, 35\% e 12\%).

Salienta-se que o item drogas é uma interpretação do trabalho que abrange a oralidade dos entrevistados que se referiam ao uso/consumo de drogas e tráfico de drogas. Destaca-se ainda que a maioria dos entrevistados mencionava as erosões ou suas imediações como locais de muitos crimes, dentre eles assassinatos, uso e tráfico de drogas.

Quanto à saúde, nessa análise foi possível verificar que 19\% dos entrevistados nunca receberam visitas de agentes de saúde e/ou sanitários. No que diz respeito ao atendimento médico, observa-se que $66 \%$ dos moradores obtêm tratamento médico pelo Sistema Único de Saúde (SUS), sendo que entre esses, a maioria informou receber um atendimento regular, destacando-se um percentual acentuado de 18\% indicando receber um mau atendimento.

No que se refere aos serviços de transporte coletivo, $68 \%$ dos entrevistados consideraram o transporte coletivo de boa qualidade e fácil acesso, sendo que quase a metade dos entrevistados usufruía desse serviço, utilizando em média uma ou duas conduções para chegar ao seu destino. Destaca-se que aproximadamente $23 \%$ dos moradores possuem carro e $5 \%$ dispõem de moto. Entre esses moradores que possuem seu próprio meio de locomoção, não existe a opção por deslocamento no transporte coletivo.

Quando perguntados sobre o tipo de lazer que desfrutam em momentos de folga, os moradores apontaram vários elementos, com destaque do percentual elevado de referências a igreja e a televisão como fonte de lazer. A igreja apareceu na resposta de 61\% dos moradores, seguidos de um expressivo percentual de $46 \%$ de referências à televisão como fonte de lazer.

Com relação às vantagens em residir no local, tranquilidade e localização apareceram como os principais elementos. Considerando o percentual de $42 \%$ dos entrevistados que avaliaram o bairro como violento, pode parecer contraditório o fato de a tranquilidade aparecer como a principal vantagem dos bairros analisados. Todavia, essa contradição é apenas aparente, pois se verificou que a percepção de tranquilidade dos moradores está vinculada a muitos outros parâmetros além da violência. Foram citados a relação de vizinhança, proximidade com os parentes, casa própria, valor acessível do aluguel e até mesmo o fato de esses locais apresentarem uma maior tranquilidade no trânsito, menor nível de ruído 
e, muitas vezes, maior interação com ambientes dotados de cobertura natural.

Quanto às desvantagens, as erosões foram apontadas em $72 \%$ das vezes como elemento que interfere negativamente no cotidiano de quem habita o local (Gráfico 4). Escola, saúde e lazer também foram mencionados com grande incidência pelos moradores, revelando uma carência de equipamentos e serviços relacionados a esses itens. Constatou-se que $74 \%$ das respostas obtidas incluem algum tipo de prejuízo ao morador.

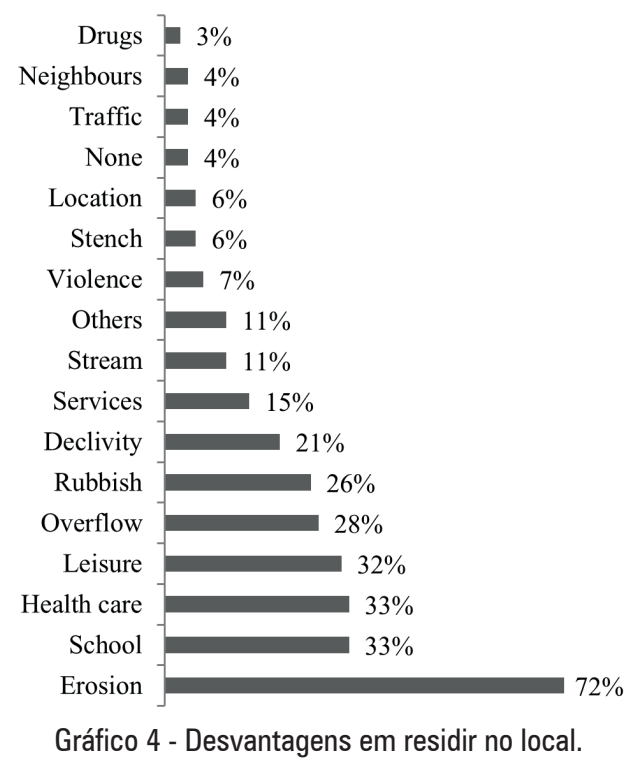

Fonte: Jesus (2013).

Entre os relatos de prejuízos vinculados às incisões erosivas, destaca-se o mau cheiro, apontado por $18 \%$ dos moradores. O mau cheiro é um tipo de poluição invisível e silênciosa cuja magnitude não pode ser transmitida genuinamente nem por fotos nem por filmagem. Quando se fala que uma voçoroca causa um impacto visual e apresenta-se uma foto dela, é possível se chocar com a imagem tanto como com uma visualização ao vivo do fenômeno, mas com o mau odor isso não é possível. Para se ter uma dimensão do grau desse impacto faz-se necessário vivenciá-lo. No entanto, na realidade, nem ravinas nem voçorocas exalam por si sós 
odores, sejam eles bons ou maus. A causa do mau cheiro não é a erosão, mas sim o fato de sobre ela serem lançados lixos e por vezes águas servidas pela própria população e que nem sempre é a local. Com isso as erosões podem contibuir para o surgimento de um outro impacto ambiental que interfere diretamente na qualidade de vida e na saúde pública: o mau cheiro.

A presença de insetos também foi apontada como um prejuízo relacionado à erosão por 14\% dos moradores. Em geral, o mesmo lixo lançado nas incisões erosivas, e que ao entrar em decomposição causa os odores desagradáveis, também favorece a proliferação de insetos como baratas, moscas e mosquitos. Foi mencionada ainda a presença de roedores como ratos por $6 \%$ dos moradores. Animais peçonhentos como escorpiões e cobras também foram relatados por alguns moradores, por se tratar de animais que encontram abrigo fácil entre o entulho e o mato alto existente dentro das erosões. Não se pode deixar de mencionar que a presença de lixo ainda propicia a existência de criadouros de mosquitos (Aedes Aegypti) transmissores do vírus da dengue, sendo que 6\% dos moradores mencionaram a existência de vetores de doenças como um prejuízo a ser associado às erosões.

O risco às crianças foi referido por $4 \%$ dos moradores entrevistados e deve ser levado em consideração, uma vez que $20 \%$ da população abordada na pesquisa correspondem a crianças de 0 a 14 anos. Tal risco envolve desde contaminação até mesmo quedas e cortes com objetos perfurocortantes existentes dentro da incisão.

Diante de todas as dificuldades evidenciadas anteriormente quanto às erosões e os problemas resultantes da sua dinâmica evolutiva, quando perguntados se gostariam de se mudar, surpreendentemente, $61 \%$ dos moradores entrevistados disseram que não gostariam de se mudar. Contudo, uma maioria de 52\% desses moradores não especificou o motivo do desejo de permanência no bairro. Os que justificaram seu desejo de permanência mencionaram os seguintes itens: gosto pelo local, vizinhança, acesso a serviços, ausência de perigo para casa, recuperação da área degradada pela erosão. Destacaram-se como justificativa pela opção de permanência no local, a tranquilidade e a casa própria, cada um com $9 \%$ de menções dos entrevistados.

Observa-se também que há um desconhecimento, por parte dos moradores, dos danos e riscos a que estão submetidos na presença da 
erosão. Em algumas casas entrevistadas, o morador não possuía nem mesmo seu próprio quintal, pois foi erodido pelo avanço da erosão, e ainda assim o morador entrevistado alegou não haver prejuízo algum. A erosão passa a fazer parte do cotidiano das pessoas, assim como a rua, a casa, os vizinhos (Figura 3). Pode-se considerar também que o não reconhecimento do risco inerente às incisões erosivas seja um ato inconsciente dos moradores, diante de uma realidade implacavelmente cruel, de modo que a única forma de conseguir dormir todos os dias em tais condições de risco seja ignorando sua presença.

A Figura 3 revela essa relação com a erosão, onde uma família com onze pessoas, sendo cinco crianças, é fotografada dentro de uma voçoroca da área pesquisada como se posassem para uma foto na frente de casa ou na praça do bairro. Essas pessoas ignoram os riscos a sua integridade física e saúde diante dos eventuais movimentos de massa e contaminação da área com o lixo.

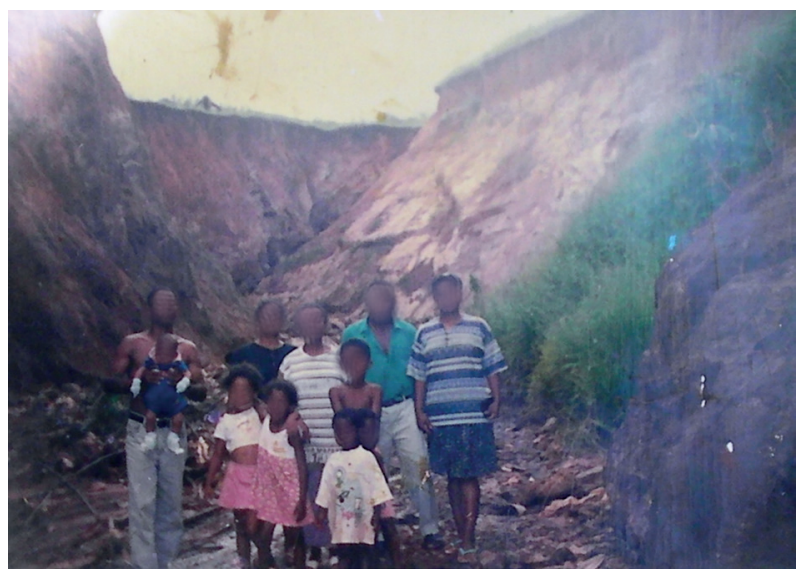

Figura 3 - Família fotografada dentro de voçoroca em Anápolis.

Fonte: Jesus, 2013 (acervo da família, cedido espontaneamente à pesquisa no ato da realização das entrevistas). Os rostos foram ocultados para preservar a identidade das fontes.

No intuito de verificar a articulação sociopolítica dos moradores diante da realidade marcada pela presença de erosões com a qual convivem diariamente, foi perguntado aos moradores o que eles e seus vizinhos fizeram para resolver o problema (Gráfico 5). Foram apontadas 
diversas ações, mas destacou-se um percentual de 15\% de moradores que afirmaram nunca ter feito nada e de 13\% que afirmaram não saber informar sobre as ações.

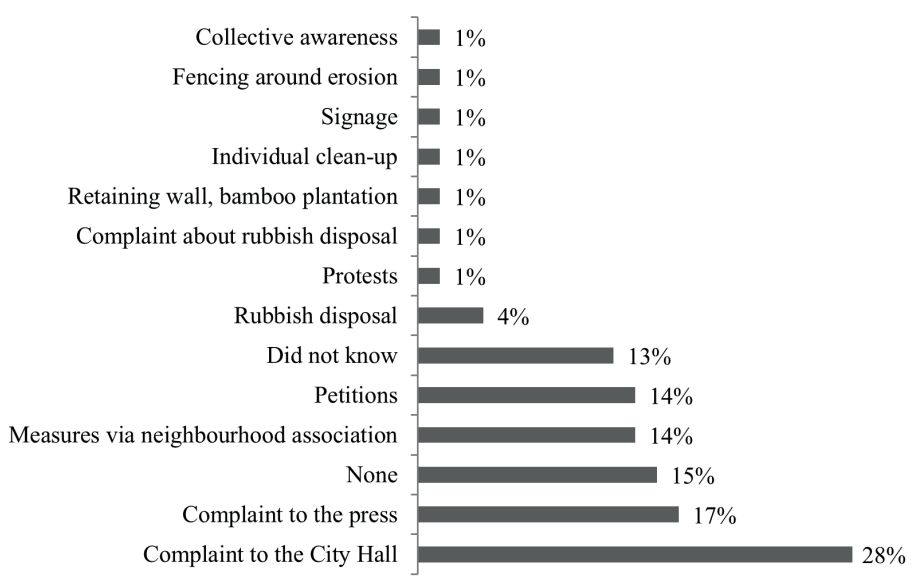

Gráfico 5 - Ações tomadas pelos moradores para resolução do problema.

Fonte: Jesus (2013).

A campeã das ações apontadas pelos moradores foi a reclamação na prefeitura, apontada por $28 \%$ dos moradores, seguida de reclamação na imprensa, que foi mencionada por $17 \%$ dos entrevistados. Ações via presidente de bairro e abaixo-assinados foram, cada um, apontados por 14\% dos entrevistados. Além disso, foram mencionadas outras ações, mas por um percentual reduzido de moradores. O que se observa desse quadro é uma baixa articulação entre os moradores. Em grande parte, eles nunca fizeram nada para solucionar os problemas. E entre os que tomaram alguma atitude, muitas das vezes esta foi feita de maneira isolada, sem envolver a vizinhança. Alguns moradores nem têm conhecimento da associação de moradores e sequer conhecem o presidente de bairro.

\section{Considerações finais}

Dos estudos realizados junto à população, percebe-se que os danos ao meio ambiente oriundos dos processos erosivos lineares do tipo 
voçoroca afetam a qualidade de vida e geram riscos para a saúde e para a própria vida, fazendo necessária a atuação preventiva e, em certos casos, mitigadora desses problemas por parte do poder público.

É de fundamental importância que os vários profissionais que trabalham com a questão dos processos erosivos enxerguem a erosão de forma mais ampla e integradora, de modo a alcançar a cidadania e a dignidade dos moradores que convivem com esses processos. O gestor público, por exemplo, deve ampliar a visão da erosão como um problema administrativo para um problema de segurança pública, desigualdade social, educação e saúde pública.

Essa atuação do poder público deve se iniciar com a elaboração do Plano Diretor e continuar por meio da elaboração de normas apropriadas de ocupação e uso do solo que inclusive prevejam a implantação de obras básicas de infraestrutura. Para a efetividade dessas normas, faz-se necessário intensificar as ações voltadas para a educação ambiental formal e não formal da população e a prática de atos de fiscalização, lembrando que o educar previne evitando danos futuros.

Acima de tudo, educar para uma conscientização da realidade espacial vivida permite o exercício da cidadania, uma vez que dá possibilidades para que o sujeito, de forma individual ou coletiva, possa intervir e modificar sua realidade. A alienação com relação ao espaço habitado, por vezes, pode levar os moradores afetados direta e profundamente por esse fenômeno a terem sua situação agravada, com lançamento de águas servidas e de lixo nas bordas e dentro da incisão erosiva, além de impedir a articulação para resolução do problema e/ou pressão ao poder público no sentido de mitigar o problema.

Tal situação decorre da falta de conhecimento do espaço em que habitam, dos riscos a que estão sujeitos e dos seus direitos como cidadãos. Logo, a qualidade de vida tem uma relação direta com o conhecimento do espaço vivido. Isso suscita, portanto, a necessidade de educação ambiental para cidade e para o espaço. Essa falta de conhecimento não parece ser uma questão de classe social ou de escolaridade, pois ao longo da pesquisa percebeu-se que muitas pessoas desconhecem o relevo e a hidrografia que configuram a paisagem onde moram.

Ações educativas que permitam aos habitantes conhecerem o espaço que habitam, a geologia, o relevo, a hidrografia e os solos são, portanto, de fundamental importância. Esse conhecimento localizado, regionalizado, 
do espaço que habitam permite uma maior intimidade dos indivíduos com seu local, com sua cidade e uma consciência maior quanto aos riscos de ocupação em áreas do meio físico mais sensíveis ambientalmente. Assim, promove-se uma consciência espacial e ambiental que tende a se refletir no agir cotidiano de cada um, como, por exemplo, conscientizando sobre empreendimentos imobiliários que desconsideram as questões ambientais, ou mesmo respeitando as áreas permeáveis de cada quintal ou ainda não jogando lixo dentro de voçorocas. Essas e tantas outras ações podem ter cunho preventivo e mitigador de processos erosivos e outras formas de degradação do solo e impacto ambiental.

\section{Apoio Financeiro}

Os dados desta publicação são fruto de pesquisa de doutorado que recebeu apoio financeiro da CAPES e do CNPq entre os anos de 2008 e 2012.

\section{Referências}

ANÁPOLIS (Município). Lei Complementar nº 128, de 10 de outubro de 2006. Plano Diretor Participativo do Município de Anápolis. Anápolis, GO: Prefeitura Municipal, 2006.

BERTONI, J.; LOMBARDI NETO, F. Conservação do solo. 2. ed. São Paulo: Ícone, 1999.

BRASIL. Decreto $\mathrm{n}^{0}$ 7.655, de 23 de dezembro de 2011. Regulamenta a Lei $\mathrm{n}^{\mathrm{o}}$ 12.382, de 25 de fevereiro de 2011, que dispõe sobre o valor do salário mínimo. Diário Oficial [da] União, Brasília, DF, Seção 1, n. 247, 26 dez. 2011.

CARLOS, A. F. A. A cidade. São Paulo: Contexto, 2001.

COELHO, M. C. N. Impactos ambientais em áreas urbanas: teorias, conceitos e métodos de pesquisa. In: GUERRA, A. J. T.; CUNHA, S. B. da (Ed.). Impactos ambientais urbanos no Brasil. Rio de Janeiro: Bertrand Brasil, 2001. p. 19-45.

IBGE - Instituto Brasileiro de Geografia e Estatística. Censo Demográfico 2010. Disponível em: <http://censo2010.ibge.gov.br/resultados>. Acesso em: 5 dez. 2012.

JESUS, A. S. de. Impactos ambientais na alta bacia urbana do rio das Antas em Anápolis, GO. 2007. 159 f. Dissertação (Mestrado em Geografia) - Instituto de Estudos Socioambientais, Universidade Federal de Goiás, Goiânia, 2007.

JESUS, A. S. de. Investigação multidisciplinar de processos erosivos lineares: estudo de caso da cidade de Anápolis, GO. 2013. 340 f. Tese (Doutorado 
em Geotecnia) - Curso de Geotecnia, Departamento de Engenharia Civil, Universidade de Brasília, Brasília, 2013.

JESUS, A. S. de; LOPES, L. M.; CARVALHO, J. C. de. Erosão acelerada e suas interferências na qualidade de vida: o exemplo da alta bacia do rio das Antas na área urbana de Anápolis, GO. In: SIMPÓSIO BRASILEIRO DE GEOGRAFIA FÍSICA APLICADA, 13., 2009, Viçosa. Anais... Viçosa: UFV, 2009.

SANTOS, Á. R. dos. Diálogos geológicos: é preciso conversar mais com a terra. São Paulo: O Nome da Rosa, 2008.

Andrelisa Santos de Jesus - possui graduação em Geografia pela Universidade Estadual de Goiás, Mestrado em Geografia pela Universidade Federal de Goiás e Doutorado em Geotecnia pela Universidade de Brasília. Atualmente é Professora Adjunta da Universidade Federal de Goiás.

José Camapum de Carvalho - é graduado em Engenharia Civil pela Universidade de Brasília, em Administração pelo Centro de Ensino Unificado de Brasília e em Direito pelo Centro Universitário de Brasília. Mestrado em Engenharia Civil (Geotecnia) pela Universidade Federal da Paraíba e Doutorado em Engenharia Civil (Geotecnia) pelo Institut National dês Sciences Appliquées de Toulouse - França. Pós-doutorado em Geotecnia na Université Laval, Quebec-Canadá. Atualmente é Professor Titular da Universidade de Brasília e integra o quadro de docentes do Programa de Pós-Graduação em Geotecnia da Universidade de Brasília.

Contribuição de cada autor no desenvolvimento do artigo

Os autores trabalharam conjuntamente com contribuições científicas e intelectuais ao estudo. O primeiro autor realizou a coleta, tabulação, interpretação de dados e preparação inicial do manuscrito. O segundo autor colaborou com a discussão dos resultados, oferecendo substanciais contribuições quanto à interpretação dos dados.

Recebido para publicação em 18 de outubro de 2016 Aceito para publicação em 21 de novembro de 2016 